NASA/TM-2018-219757

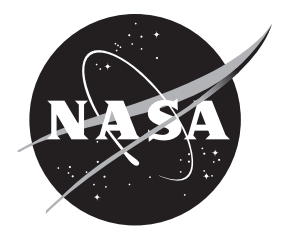

\title{
Modeling the Effect of Damage on Electrical Resistivity of Melt-Infiltrated $\mathrm{SiC} / \mathrm{SiC}$ Composites
}

Roy M. Sullivan

Glenn Research Center, Cleveland, Ohio

Eric H. Baker

Connecticut Reserve Technologies, Inc., Cleveland, Ohio

Craig E. Smith

Glenn Research Center, Cleveland, Ohio

Gregory N. Morscher

The University of Akron, Akron, Ohio 


\section{NASA STI Program . . . in Profile}

Since its founding, NASA has been dedicated to the advancement of aeronautics and space science. The NASA Scientific and Technical Information (STI) Program plays a key part in helping NASA maintain this important role.

The NASA STI Program operates under the auspices of the Agency Chief Information Officer. It collects, organizes, provides for archiving, and disseminates NASA's STI. The NASA STI Program provides access to the NASA Technical Report Server-Registered (NTRS Reg) and NASA Technical Report ServerPublic (NTRS) thus providing one of the largest collections of aeronautical and space science STI in the world. Results are published in both non-NASA channels and by NASA in the NASA STI Report Series, which includes the following report types:

- TECHNICAL PUBLICATION. Reports of completed research or a major significant phase of research that present the results of NASA programs and include extensive data or theoretical analysis. Includes compilations of significant scientific and technical data and information deemed to be of continuing reference value. NASA counter-part of peer-reviewed formal professional papers, but has less stringent limitations on manuscript length and extent of graphic presentations.

- TECHNICAL MEMORANDUM. Scientific and technical findings that are preliminary or of specialized interest, e.g., "quick-release" reports, working papers, and bibliographies that contain minimal annotation. Does not contain extensive analysis.
- CONTRACTOR REPORT. Scientific and technical findings by NASA-sponsored contractors and grantees.

- CONFERENCE PUBLICATION. Collected papers from scientific and technical conferences, symposia, seminars, or other meetings sponsored or co-sponsored by NASA.

- SPECIAL PUBLICATION. Scientific, technical, or historical information from NASA programs, projects, and missions, often concerned with subjects having substantial public interest.

- TECHNICAL TRANSLATION. Englishlanguage translations of foreign scientific and technical material pertinent to NASA's mission.

For more information about the NASA STI program, see the following:

- Access the NASA STI program home page at http://www.sti.nasa.gov

- E-mail your question to help@sti.nasa.gov

- Fax your question to the NASA STI Information Desk at 757-864-6500

- Telephone the NASA STI Information Desk at 757-864-9658

- Write to:

NASA STI Program

Mail Stop 148

NASA Langley Research Center Hampton, VA 23681-2199 
NASA/TM-2018-219757

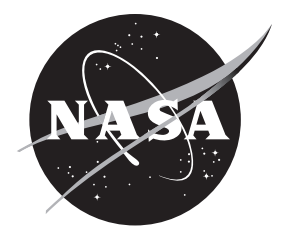

\section{Modeling the Effect of Damage on Electrical Resistivity of Melt-Infiltrated $\mathrm{SiC} / \mathrm{SiC}$ Composites}

Roy M. Sullivan

Glenn Research Center, Cleveland, Ohio

Eric H. Baker

Connecticut Reserve Technologies, Inc., Cleveland, Ohio

Craig E. Smith

Glenn Research Center, Cleveland, Ohio

Gregory N. Morscher

The University of Akron, Akron, Ohio

National Aeronautics and

Space Administration

Glenn Research Center

Cleveland, Ohio 44135 


\section{Acknowledgments}

This work was funded by the Transformational Tools and Technologies (TTT) Project under NASA's Aeronautics Research Mission Directorate (ARMD) and by NASA's Space Technology Mission Directorate (STMD) through the NASA Glenn Center Innovation Fund (CIF).

This work was sponsored by the Transformative Aeronautics Concepts Program.

Trade names and trademarks are used in this report for identification only. Their usage does not constitute an official endorsement, either expressed or implied, by the National Aeronautics and Space Administration.

Level of Review: This material has been technically reviewed by technical management.

Available from

NASA STI Program

Mail Stop 148

NASA Langley Research Center

Hampton, VA 23681-2199
National Technical Information Service 5285 Port Royal Road Springfield, VA 22161

703-605-6000

This report is available in electronic form at http://www.sti.nasa.gov/ and http://ntrs.nasa.gov/ 


\title{
Modeling the Effect of Damage on Electrical Resistivity of Melt-Infiltrated $\mathrm{SiC} / \mathrm{SiC}$ Composites
}

\author{
Roy M. Sullivan \\ National Aeronautics and Space Administration \\ Glenn Research Center \\ Cleveland, Ohio 44135 \\ Eric H. Baker \\ Connecticut Reserve Technologies, Inc. \\ Cleveland, Ohio 44135 \\ Craig E. Smith \\ National Aeronautics and Space Administration \\ Glenn Research Center \\ Cleveland, Ohio 44135 \\ Gregory N. Morscher \\ The University of Akron \\ Akron, Ohio 44325

\section{Summary}

Electrical resistivity (ER) measurements are a possible health monitoring technique for ceramic matrix composite components in future aerospace applications. In order to use ER measurements to detect and identify damage, it is necessary to understand how each specific damage state will affect the ER response. In this report, finite element models are developed and applied to quantify the effect of specific damage states on the ER response in a melt-infiltrated $\mathrm{SiC}$ fiber-reinforced $\mathrm{SiC}$ composite. The ER of several damage states are calculated by simulating the electric current flow through the damaged microstructure. This is achieved by performing the numerical solution of the steady-state conservation of charge density equation. Numerical results reveal that cracking of the intertow matrix has the most profound effect on the composite ER. Also, fiber/matrix debonding at matrix cracks in the $0^{\circ}$ tows (tows aligned with the loading direction) may cause a significant increase in the ER, but only if the fiber coating resistivity is $1,000 \Omega$-cm or less. Cracks in the $90^{\circ}$ tows and the crack opening displacement have very little effect on the composite ER.

\section{Nomenclature}

3D three-dimensional

5HS five-harness satin

A cross-sectional area of minicomposite; area of vertical boundary in two-dimensional transverse flow model

$A_{c c} \quad$ cross-sectional area of single concentric cylinder assemblage

CCA concentric cylinder assemblage

CMC ceramic matrix composite

COD crack opening displacement 


$\begin{array}{ll}\text { CVI } & \text { chemical vapor infiltration } \\ \text { epi } & \text { ends per inch } \\ \text { ER } & \text { electrical resistivity } \\ h & \text { unit cell height; ply thickness } \\ I & \text { total electric current } \\ j & \text { current density } \\ j_{x}, j_{y}, j_{z} & \text { current density in x-, y-, and z-directions, respectively } \\ L & \text { width of finite element mesh used to calculate tow transverse resistivity } \\ \text { MI } & \text { melt infiltration } \\ N & \text { number of fibers in minicomposite } \\ R & \text { resistance of minicomposite } \\ R_{c c} & \text { resistance of concentric cylinder assemblage } \\ \text { RSS } & \text { residual sum of squares } \\ V & \text { electric potential } \\ \Delta V & \text { imposed electric potential differential } \\ w & \text { unit cell length and width; tow spacing } \\ \rho & \text { electrical resistivity } \\ \tilde{\rho} & \text { effective longitudinal resistivity of minicomposite; effective resistivity of composite } \\ \tilde{\rho}_{c c} & \text { effective longitudinal resistivity of concentric cylinder assemblage } \\ \rho_{i} & \text { resistivity of constituent (fiber } f \text {, chemical-vapor-infiltrated matrix CVI, or boron nitride BN) } \\ \tilde{\rho}_{T} & \text { effective transverse resistivity } \\ \rho_{x}, \rho_{y}, \rho_{z} & \text { resistivity in x-, y-, and z-directions, respectively } \\ \sigma & \text { electrical conductivity } \\ \sigma_{x}, \sigma_{y}, \sigma_{z} & \text { conductivity in x-, y-, and z-directions, respectively } \\ \varphi_{i} & \text { volume fraction of minicomposite constituent (fiber } f \text {, chemical-vapor-infiltrated matrix CVI, } \\ & \text { and boron nitride } B N \text { ) } \\ & \end{array}$

\subsection{Introduction}

Ceramic matrix composites (CMCs) are an emerging class of materials that have been proposed for many future high-temperature applications in the aerospace industry. Combustor liners, vanes, and mixers in jet engines and thrust chambers for in-space propulsion are just a few examples of the many proposed applications. In order to use CMCs in future aerospace applications, it will be necessary to develop a means of monitoring the structural health of the CMC component. Cracking features such as type of cracking (i.e., which constituents), extent of cracking, and crack density are all critical indicators of the structural health and remaining life of CMC components.

Electrical resistivity (ER) measurements are one possible health monitoring technique (Smith, Morscher, and Xia, 2008 and 2011; and Morscher and Gordon, 2017). The advantages of ER are that it is simple to employ and it can be used to detect damage either in situ or postdamage. One shortcoming with ER is that it is not an imaging technique, so it is not possible to discern the cracking features with an ER reading alone. An increase in the ER merely indicates that some damage has occurred. 
In order to use ER measurements to detect and identify cracking features, one must first understand how each specific damage state will affect the ER response. The objective of this report is to develop and apply finite element models to quantify the effect of specific damage states on the ER response in a specific CMC.

The ER is determined by simulating the electric current flow through the composite microstructure. This is achieved by performing the numerical solution of the steady-state conservation of charge density equation. The numerical solutions are performed using the COMSOL Multiphysics finite element program (COMSOL, 2016). A representative volume of the composite, or repeating unit cell, is adopted to represent the composite's periodic microstructure. Finite element models of the unit cell are developed and utilized to calculate the ER in a variety of damage states. The effect of certain cracking features such as type of cracking, crack density, fiber/matrix debonding, and crack opening displacement are investigated. The numerical solution results reveal which cracking features have a significant effect on the composite ER and which features are insignificant.

The composite material that is the subject of this study consists of four constituents: fibers, a fiber coating, an intratow matrix, and an intertow matrix. The fiber resistivity value was obtained from direct measurements made previously (Smith, 2016). Resistivity of the intratow matrix and intertow matrix is estimated through a comparison of previously obtained ER measurements to analytical and numerical model results, respectively. A good estimate for the resistivity of the fiber coating is currently not available. Numerical solutions are performed with a variety of fiber coating resistivity values to show the effect of this parameter on the solution results. The ER of some or all of the composite constituents are known to vary with temperature. However, this report is focused on the room-temperature response only.

\subsection{Material Description and Microstructure Idealization}

The composite material that will be the focus of this study is a Sylramic ${ }^{\mathrm{TM}}-\mathrm{iBN}$ (COI Ceramics, Inc.) fiber-reinforced melt-infiltrated (MI) silicon carbide ( $\mathrm{SiC}$ ) composite. The material is reinforced with a five-harness satin (5HS) woven fabric, with a tow spacing of 6.7 ends per $\mathrm{cm}$ (17 ends per inch, epi). Each tow contains 800 Sylramic $^{\mathrm{TM}}$-iBN fibers with an average fiber radius of $5 \mu \mathrm{m}$. The composite fiber volume fraction is approximately 36 percent.

Composite fabrication involves multiple infiltration cycles. The fiber preform was first chemical vapor infiltrated (CVI) with silicon-doped boron nitride (BN) to coat the fibers. The fiber coating thickness is approximately $0.5 \mu \mathrm{m}$. The coated fabric was then infiltrated with a layer of CVI SiC. Next, a roomtemperature slurry of SiC particles was infiltrated into the open porosity. Finally, liquid Si was absorbed into much of the remaining porosity by means of MI at a temperature near $1400{ }^{\circ} \mathrm{C}$ (DiCarlo, 2004 and Smith, 2016). Material processing was performed at GE Power Systems Composites (Newark, DE).

Figure 1 shows the composite microstructure. Two orthogonal groups of fiber tows are evident in the photomicrograph: tows aligned with the loading direction and those aligned perpendicular to the loading direction. The latter group of tows are also aligned normal to the image plane. Tows that are aligned with the loading direction will herein be referred to as " $0{ }^{\circ}$ tows," and those aligned orthogonal to the loading direction will be referred to as " $90^{\circ}$ tows."

Note that the tows assume a nearly elliptic cross section. Microscopic examination reveals that the nominal tow width is $1400 \mu \mathrm{m}$ and the nominal tow height is $120 \mu \mathrm{m}$. The magnified view of a tow shows the individual fibers surrounded by the BN fiber coating. The CVI SiC matrix occupies the spaces within the tow, between the individual fibers. The volumes between the tows are occupied by a mixture of MI Si and $\mathrm{SiC}$ particles. This intertow matrix will herein be referred to as the "MI Si-SiC matrix." 


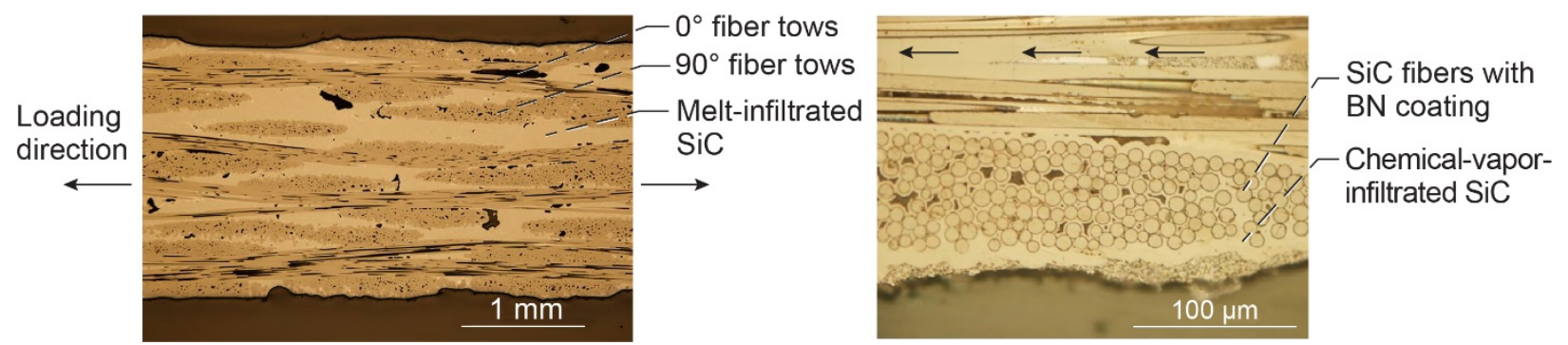

Figure 1.-Sylramic ${ }^{T M}$-iBN (COI Ceramics, Inc.) fiber-reinforced melt-infiltrated SiC composite microstructure.

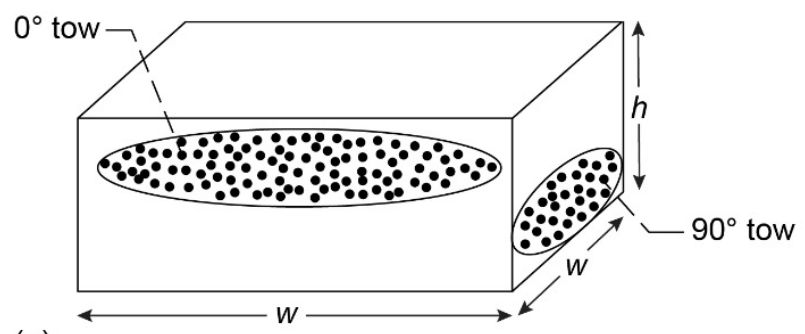

(a)

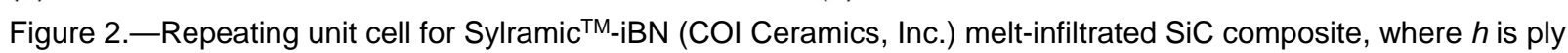
thickness and $w$ is average tow spacing. (a) With two full tows. (b) With one $0^{\circ}$ tow and two $90^{\circ}$ half tows.

The effects of damage on the composite ER will be assessed using a representative volume element (or unit cell) of the composite. A unit cell is the smallest subvolume that contains a sufficient description of the periodic microstructure and whose response is representative of the macroscopic behavior. A unit cell of the material of interest is shown in Figure 2(a). It is a square prism consisting of two orthogonal elliptical prisms (one on top of the other) with MI Si-SiC matrix occupying the interstitial spaces. The unit cell has height $h$, which is equal to one ply thickness, and length and width $w$, which is equal to the tow spacing. The tow spacing for this material is $w=1,492 \mu \mathrm{m}$ (6.7 tows per centimeter), and a nominal ply thickness is $h=250 \mu \mathrm{m}$. The elliptical prisms represent the tows and, as such, possess the dimensions 1,400 by 120 by $1,492 \mu \mathrm{m}$. An equivalent unit cell may be obtained by replacing the $90^{\circ}$ tow with two $90^{\circ}$ half tows (Figure 2(b)).

\subsection{Electrical Resistivity Measurements and Constituent Values}

A summary of the volume fractions and resistivity values of all the constituents are listed in Table I. The volume fractions were obtained from Smith (2016). The volume fractions of the MI Si and the SiC particles reported by Smith have been combined, since herein these two constituents are treated as a mixture. Smith reported a total composite porosity of 4 percent. The 4-percent porosity has been evenly distributed to the CVI SiC and MI Si-SiC matrix volume fractions to yield the volume fractions shown in Table I.

Smith (2016) measured the resistivity of unstressed, undamaged composite specimens using the fourpoint method. He also measured the resistivity of Sylramic ${ }^{\mathrm{TM}}$-iBN fibers in a similar manner. Smith reported an average room-temperature resistivity of $0.0275 \Omega$-cm for the undamaged composite and a room temperature resistivity of $0.23 \Omega$-cm for the Sylramic ${ }^{\mathrm{TM}}-\mathrm{iBN}$ fibers. 
TABLE I.-VOLUME FRACTIONS AND ROOM-TEMPERATURE

RESISTIVITY VALUES OF COMPOSITE CONSTITUENTS

\begin{tabular}{|l|l|c|c|l|}
\hline \multicolumn{1}{|c|}{} & $\begin{array}{c}\text { Volume } \\
\text { fraction }\end{array}$ & $\begin{array}{c}\text { Resistivity, } \\
\Omega-c m\end{array}$ & \multicolumn{1}{|c|}{ Resistivity source } \\
\hline \multicolumn{1}{|c|}{ Undamaged composite } & ---- & 0.0275 & \multicolumn{1}{|c|}{ Smith (2016) } \\
\hline & $\begin{array}{l}\text { Sylramic } \\
\text { fibers }\end{array}$ & 0.36 & 0.23 & \multicolumn{1}{|c|}{ Smith (2016) } \\
\cline { 2 - 5 } Constituent $^{\mathrm{a}}{ }^{\mathrm{TM}}$ & CVI SiC matrix & 0.26 & 47 & $\begin{array}{l}\text { Deduced from Hi-Nicalon } \\
\text { minicomposite electrical resistivity measurements by } \\
\text { Almansour (2017). }\end{array}$ \\
\cline { 2 - 5 } & BN fiber coating & 0.07 & $10^{0}$ to $10^{14}$ & $\begin{array}{l}\text { Expanded range of values. Initial range obtained from } \\
\text { literature search. }\end{array}$ \\
\cline { 2 - 5 } & $\begin{array}{l}\text { MI Si-SiC } \\
\text { matrix }\end{array}$ & 0.31 & 0.00745 & $\begin{array}{l}\text { Estimated from finite element analysis results presented } \\
\text { in Section 5.0. }\end{array}$ \\
\hline
\end{tabular}

aSylramic and Hi-Nicalon are trademarks of COI Ceramics, Inc.; CVI is chemical vapor infiltration; and MI is melt infiltration.

The resistivities of the BN fiber coating, the CVI SiC matrix, and the MI Si-SiC matrix have not been measured. An estimate of the resistivity of the MI Si-SiC matrix was obtained through the analysis of the current flow through the undamaged composite. This will be discussed in Section 5.0 of this report.

$\mathrm{BN}$ is generally considered a good electrical insulator. Typical resistivity values are in the range of $10^{12}$ to $10^{15} \Omega$-cm (Accuratus, 2013; Ceratec Technical Ceramics BV, 2018; and Precision Ceramics, 2018). However, much lower values have also been reported (see Bousetta, et al., 1996 and Aldalbahi, Zhou, and Feng, 2015). The variation in the ER of BN is due to a number of factors including the crystalline form, the crystallographic direction, and the presence of any dopants. Since the resistivity of the BN fiber coating in this material is unknown, it will be treated as a variable in the following discussions and numerical analysis solutions. In the event that the BN fiber coating resistivity falls outside the range of BN resistivity values found in the literature, an expanded range of possible values from $10^{0}$ to $10^{14} \Omega$-cm will be considered.

The resistivity of the CVI SiC matrix may be deduced from the experimental results from Almansour (2017). In these experiments, the ER of Hi-Nicalon ${ }^{\mathrm{TM}}$ Type S (COI Ceramics, Inc.)/CVI SiC

minicomposites were measured as a function of fiber volume fraction. The minicomposites were manufactured by Hyper-Therm Inc. (Huntington Beach, CA). Although the minicomposites and the standard composite were processed by different vendors, the BN fiber coating and CVI SiC matrix were deposited with similar processes in both composite forms. As a result, it is assumed that the CVI SiC matrix resistivity value deduced from the minicomposite test results are representative of the CVI SiC matrix resistivity in the standard composite.

The minicomposite may be idealized as a collection of parallel concentric cylinder assemblages (CCAs) (Jones, 1975). Each assemblage consists of a central solid cylinder representing the fiber; a thin, hollow cylinder representing the BN fiber coating; and a hollow cylinder representing the CVI SiC matrix. The longitudinal resistance of a minicomposite $R$ and of a CCA $R_{c c}$ are related by

$$
\frac{1}{R}=\sum_{i=1}^{N} \frac{1}{R_{c c_{i}}}=\frac{N}{R_{c c}}
$$

where $N$ is the number of fibers in the minicomposite. Let the effective longitudinal resistivity of the minicomposite and CCA be denoted as $\tilde{\rho}$ and $\tilde{\rho}_{c c}$, respectively. The relationship between the resistance 
and the resistivity for the minicomposite and the CCA may then be written as $R=\tilde{\rho} L / A$ and $R_{c c}=\tilde{\rho}_{c c} L / A_{c c}$, respectively. Here, $A$ is the total cross-sectional area of a minicomposite, $A_{c c}$ is the crosssectional area of a single CCA, and $L$ is the length of both the CCA and the minicomposite. Substituting the expressions for the resistances into Equation (1) and noting that $A=N A_{c c}$, one obtains $\tilde{\rho}=\tilde{\rho}_{c c}$.

Furthermore, each CCA may be envisaged as three resistors in parallel: one for the fiber $(f)$, one for the BN fiber coating, and one for the surrounding CVI matrix. Thus, the effective longitudinal resistivity of a minicomposite may be written as

$$
\frac{1}{\tilde{\rho}}=\frac{1}{\tilde{\rho}_{c c}}=\frac{\varphi_{f}}{\rho_{f}}+\frac{\varphi_{B N}}{\rho_{B N}}+\frac{\varphi_{C V I}}{\rho_{C V I}}
$$

where $\varphi_{i}$ and $\rho_{i}$ are, respectively, the volume fraction and resistivity of the three constituents within the minicomposite.

The experimental results from Almansour (2017) are shown as solid blue circular markers in Figure 3(a). A curve with the form of Equation (2) was fit through the experimental data obtained by Almansour. The optimal constituent resistivity values were obtained by minimizing the residual sum of the squares (RSS) between the experimental data and the fitted curve; namely, the optimal resistivity values of the CVI SiC matrix and Hi-Nicalon ${ }^{\mathrm{TM}}$ Type $\mathrm{S}$ fiber were determined by minimizing the RSS for each value of $\rho_{B N}$. The optimal values for $\rho_{C V I}$ and $\rho_{f}$ are plotted versus the BN resistivity in Figure 3(b). Note that the optimal value for the CVI SiC matrix does not vary with $\rho_{B N}$; it remains constant at $47 \Omega$-cm. The optimal value for the Hi-Nicalon ${ }^{\mathrm{TM}}$ Type $\mathrm{S}$ fibers is also constant, at $1.7 \Omega$-cm, for all $\rho_{B N}>10 \Omega$-cm. However, it increases to $2.4 \Omega$-cm at a BN resistivity of $1 \Omega$-cm. A plot of Equation (2) using $\rho_{f}=1.7 \Omega-\mathrm{cm}, \rho_{C V I}=47 \Omega-\mathrm{cm}$, and $\rho_{B N}=10^{5} \Omega-\mathrm{cm}$ is shown as the solid red line in Figure 3(a).

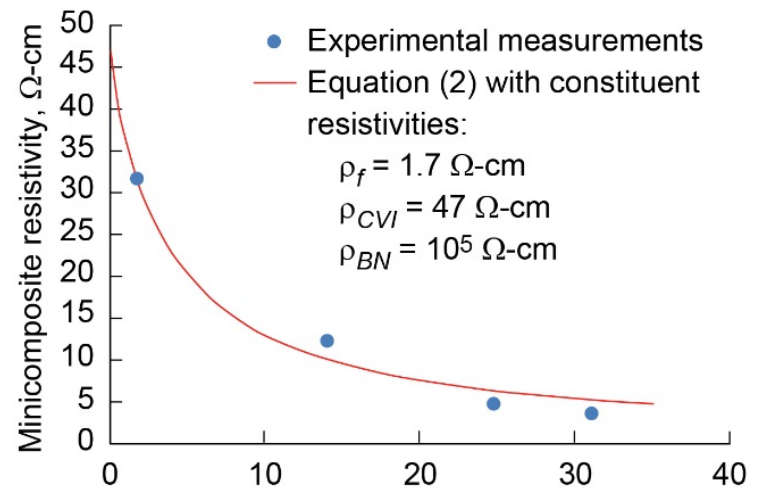

(a)

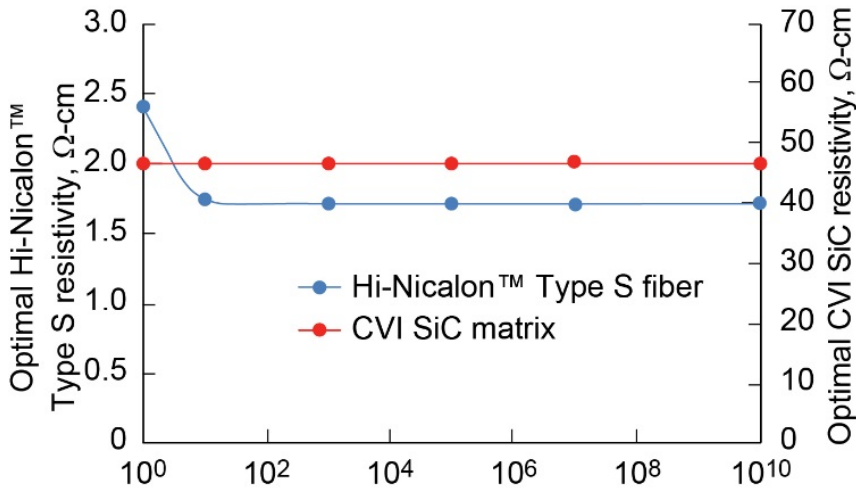

(b)

BN resistivity, $\Omega-\mathrm{cm}$

Figure 3.-Results of curve fit of Equation (2) to experimental results of Almansour (2017) for Hi-Nicalon ${ }^{\mathrm{TM}}$ Type S (COI Ceramics, Inc.)/chemical-vapor-infiltrated (CVI) SiC minicomposite. (a) Minicomposite resistivity plotted as function of fiber volume fraction. (b) Optimal values for Hi-Nicalon ${ }^{\mathrm{TM}}$ Type $\mathrm{S}$ fiber and CVI SiC matrix resistivities plotted as function of BN resistivity. 


\subsection{Description of Numerical Simulations}

The finite element analysis solutions used to calculate the ER are numerical solutions of the local conservation of charge density equation. In all solutions, steady-state conditions are assumed. The steadystate form of the conservation of charge density equation may be written in vector notation as $-\vec{\nabla} \cdot \vec{j}=0$, where $\vec{j}$ is the current density vector. Using Cartesian coordinates, the components of the current density vector are written as $j_{x}=-\sigma_{x} \partial V / \partial x, j_{y}=-\sigma_{y} \partial V / \partial y$, and $j_{z}=-\sigma_{z} \partial V / \partial z$, where $V$ is the electric potential and $\sigma_{x}, \sigma_{y}$, and $\sigma_{z}$ are the electric conductivity in the $\mathrm{x}$-, $\mathrm{y}$-, and z-directions, respectively. The conductivity is the inverse of the resistivity; that is, $\sigma=1 / \rho$. Thus, the steady-state form of the local conservation of the charge density equation in Cartesian coordinates may be written as

$$
\frac{1}{\rho_{x}} \frac{\partial^{2} V}{\partial x^{2}}+\frac{1}{\rho_{y}} \frac{\partial^{2} V}{\partial y^{2}}+\frac{1}{\rho_{z}} \frac{\partial^{2} V}{\partial z^{2}}=0
$$

The numerical solutions of Equation (3) are performed using the COMSOL Multiphysics ${ }^{\circledR}$ finite element analysis program (COMSOL, 2016). Equation (3) is included and solved in the COMSOL solution through the user-defined partial differential equation option. In all solutions, Dirichlet boundary conditions on the electric potential are applied to the finite element model. The COMSOL solutions of Equation (3) yield the local electric potential and local current density distributions within the solution domain.

\subsection{Analysis of Pristine (Undamaged) State}

A series of three-dimensional (3D) finite element analyses were performed to calculate the effective ER of the undamaged composite. A unit cell similar to that shown in Figure 2(b) was adopted for this purpose. A COMSOL-generated, half-symmetry image of the unit cell used in the analysis solutions is shown in Figure 4 . The unit cell model consists of one $0^{\circ}$ tow, two $90^{\circ}$ half tows, and MI Si-SiC matrix between the tows. The $0^{\circ}$ tow was modeled as three concentric elliptic cylinders: a solid cylinder representing all the $0^{\circ}$ fibers (grey), a thin hollow cylinder representing the $\mathrm{BN}$ fiber coating (red), and a hollow cylinder representing the CVI SiC matrix (white). The $90^{\circ}$ half tows are blue and the MI Si-SiC matrix is yellow. The size of the solid cylinder and the thicknesses of the hollow cylinders were determined from the volume fractions of the constituents listed in Table I.

The solution of Equation (3) was performed using the COMSOL Multiphysics ${ }^{\circledR}$ program (COMSOL, 2016). Boundary conditions were applied to impose a $1 \mathrm{D}$ current flowing parallel to the $0^{\circ}$ tow. A differential voltage $\Delta V$ was imposed on the mesh by applying unequal electric potentials on two opposing boundaries (Surface A and Surface B in Figure 4). The finite element solution of Equation (3) yields the electric potentials and current density throughout the unit cell. The total current flowing through the unit cell was calculated by integrating the current density over either one of the two opposing surfaces (Surface A or Surface B). The effective resistivity was calculated with $\tilde{\rho}=\Delta V h / I$, where $h$ is the height of the unit cell and $I$ is the total electric current. The resistivity of the Sylramic ${ }^{\mathrm{TM}}$-iBN fibers and the CVI $\mathrm{SiC}$ matrix listed in Table I were used as input to the model. A wide range of resistivity values for the BN fiber coating were used in these numerical solutions to illustrate the effect of the BN resistivity on the solution results. 


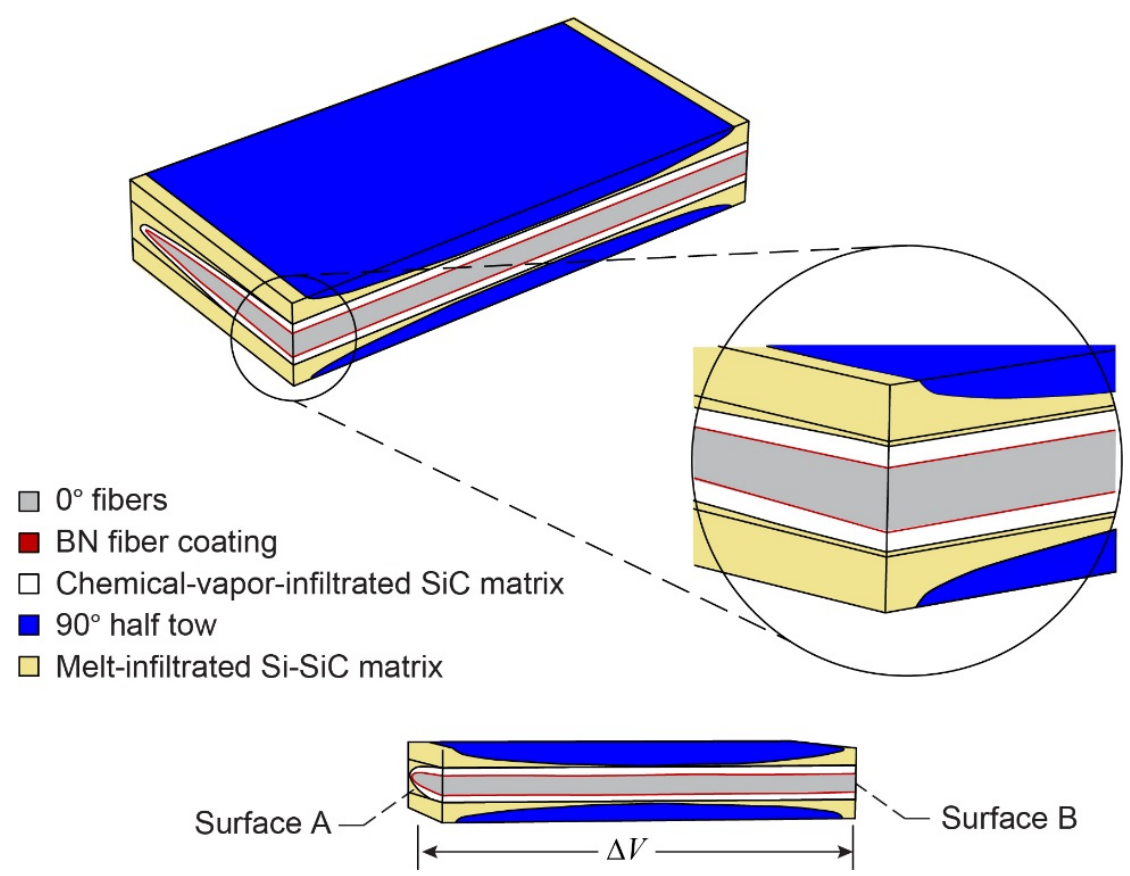

Figure 4.-One-half-symmetry image of unit cell used in three-dimensional analysis of undamaged state. Image generated by COMSOL (COMSOL, 2016). $\Delta V$ is imposed electric potential differential.

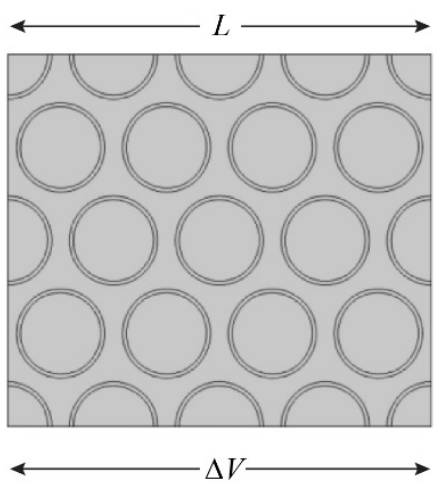

Figure 5.-Finite element model used to calculate the transverse resistivity within a tow. $L$ is width of finite element model, and $\Delta V$ is imposed electric potential differential.

The tows are transversely isotropic; they possess an electric resistivity in the fiber length direction (longitudinal) that is different from the resistivity in all directions orthogonal to the fibers (transverse). In order to obtain the transverse resistivity for the $90^{\circ}$ half tows, 2D finite element analyses were performed using COMSOL (COMSOL, 2016). A sketch of the finite element model used for this analysis is shown in Figure 5. The model consists of a hexagonal arrangement of fibers. Each fiber is surrounded by a $0.5-\mu \mathrm{m}$-thick layer of BN. The CVI SiC matrix fills the spaces between the fibers. The fiber spacing was determined from the fiber volume fraction within a tow and the size and shape of the elliptic tows. In a manner similar to the 3D unit cell solutions, an electric potential differential $\Delta V$ was imposed across the 
width of the mesh. The finite element solution of Equation (3) yields the electric potential and current density throughout the mesh. The total current flowing across the mesh was calculated by integrating the current density along either of the two vertical boundaries. The effective transverse resistivity is calculated as $\tilde{\rho}_{T}=\Delta V A / I L$, where $A$ is the area of the vertical boundary and $L$ is the width of the finite element mesh.

The results of the 2D finite element solutions are shown in Figure 6 and Figure 7. The effective transverse resistivity of a tow is plotted versus the BN resistivity in Figure 6. Contour plots of the current density within the finite element model are shown in Figure 7(a) and (b) for the solutions that used BN resistivities of $10^{2}$ and $10^{5} \Omega$-cm, respectively. Figure 6 reveals a sigmoidal relation between the effective transverse resistivity and the $\mathrm{BN}$ resistivity. At low $\mathrm{BN}$ resistivity values, the effective transverse resistivity is approximately $10 \Omega$-cm. In this region, the current flows primarily across the fibers and fiber coating (Figure 7(a)). The transverse resistivity approaches a maximum value of $198.5 \Omega$-cm at BN resistivity values above $10^{4} \Omega$-cm. In this region, the current flow is primarily in the CVI SiC matrix, between the fibers (Figure 7(b)). The results shown in Figure 6 were used as the transverse resistivity of the $90^{\circ}$ half tows in the 3D unit cell solutions.

Numerical solutions for the current flow through the 3D unit cell model were performed with a varying BN fiber coating resistivity and a varying MI Si-SiC matrix resistivity. The results of the 3D unit cell solutions are shown in Figure 8. The effective resistivity of the unit cell is plotted versus the MI Si$\mathrm{SiC}$ matrix resistivity in Figure 8(a). These solutions used a BN resistivity of $10^{5} \Omega$-cm. The results shown in Figure 8(a) reveal that the effective resistivity of the unit cell is a linear function of the MI Si$\mathrm{SiC}$ matrix resistivity and that the unit cell resistivity equals the measured undamaged composite resistivity $(0.0275 \Omega$-cm) when the MI Si-SiC matrix resistivity is $0.00745 \Omega-\mathrm{cm}$. This provides a good estimate of the ER of the MI Si-SiC matrix.

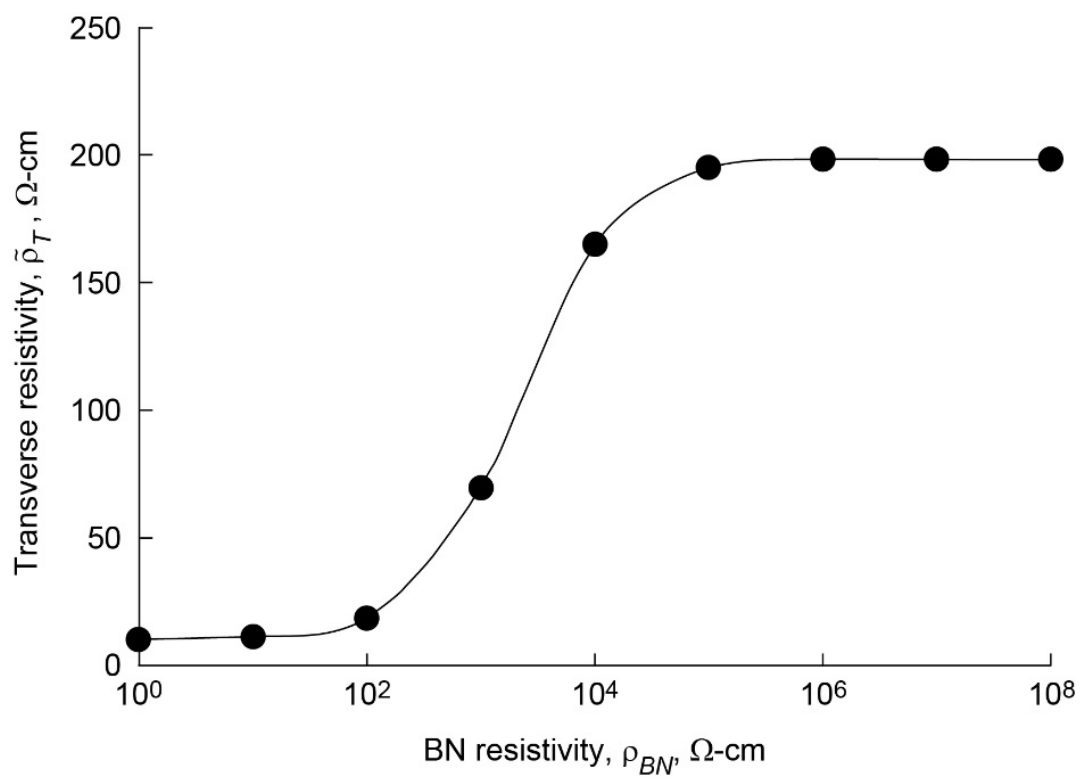

Figure 6.-Effective transverse resistivity $\tilde{\rho}_{T}$ within a tow as function of BN fiber coating resistivity $\rho_{B N}$ obtained from two-dimensional finite element simulations. Resistivity of fibers $\rho_{f}=0.23 \Omega-\mathrm{cm}$, and resistivity of chemicalvapor-infiltrated $\mathrm{SiC}$ matrix $\rho_{C V I}=47 \Omega-\mathrm{cm}$. 


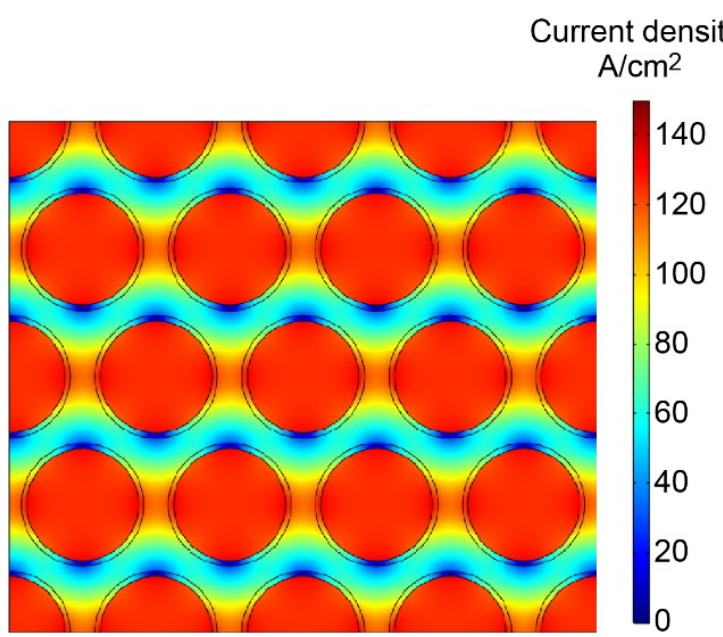

(a)

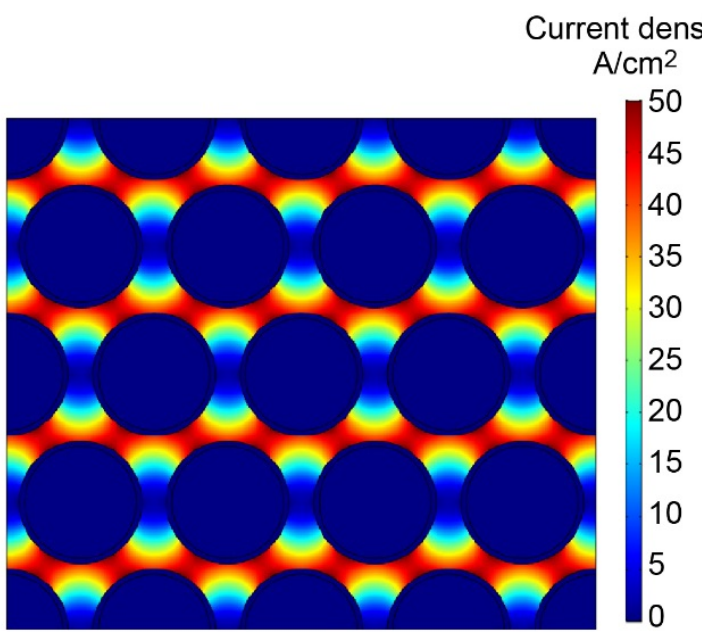

(b)

Figure 7.-Plot of current density resultant magnitude obtained in two-dimensional transverse flow analysis. Electrical potential difference of $10 \mathrm{~V}$ applied across finite element model. (a) BN resistivity $\rho_{B N}=10^{2} \Omega-\mathrm{cm}$. (b) $\rho_{B N}=10^{5} \Omega-\mathrm{cm}$.
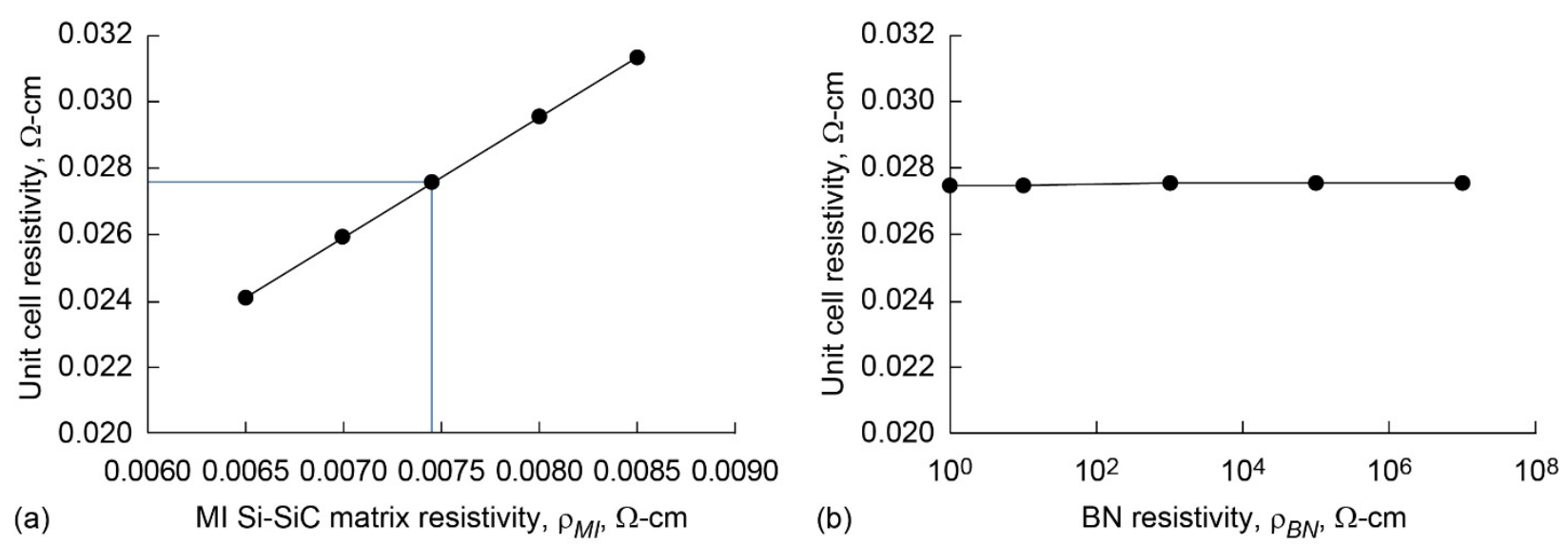

Figure 8.-Results of three-dimensional unit cell analysis solutions. (a) Unit cell effective resistivity versus meltinfiltrated (MI) Si-SiC matrix resistivity $\rho_{M I} ; \rho_{B N}=10^{5} \Omega-\mathrm{cm}$. (b) Unit cell effective resistivity versus BN fiber coating resistivity $\rho_{B N} ; \rho_{M l}=0.00745 \Omega-\mathrm{cm}$.

In Figure 8(b), the effective resistivity of the unit cell is plotted versus the BN resistivity. The results indicate that the unit cell effective resistivity is independent of the BN fiber coating resistivity. Keep in mind that the MI Si-SiC matrix and the Sylramic ${ }^{\mathrm{TM}}$-iBN fibers are the most conductive constituents, possessing ERs of 0.00745 and $0.23 \Omega$-cm, respectively. Thus, the electric current will flow primarily through these two constituents in the undamaged state. Any variations in the BN resistivity that are $1 \Omega$-cm or larger will not change the undamaged effective resistivity of the unit cell.

\subsection{Analysis of Damage States}

Damage initiates with the formation of matrix cracks in the tows that are aligned $90^{\circ}$ from the loading direction (Xia and Hutchinson, 1994). These matrix cracks are aligned perpendicular to the loading 
direction. As the applied stress is increased, the cracks propagate into the MI Si-SiC matrix and the $0^{\circ}$ tows. The portion of the cracks that extend into the $0^{\circ}$ tows are bridged by the $0^{\circ}$ tow fibers. The cracks continue to propagate as the applied stress is increased. In addition, fracture of any of the bridging fibers in the vicinity of the crack plane causes an increase in the crack opening displacement (COD), which promotes further crack propagation (Budiansky and Cui, 1994). This process continues as the cracks propagate across the width and thickness of the composite. Failure of the composite cross section occurs when a critical number of fibers have failed.

In this section, analyses are performed to determine the effective ER of the unit cell under several specific states of damage. Three damage types are considered. Type 1 damage is a crack or cracks in the $90^{\circ}$ tows only. Type 2 damage is a crack or cracks in the $90^{\circ}$ tows that also extends into the MI Si-SiC matrix. Type 3 damage is a crack or cracks in the $90^{\circ}$ tows that extends into the $\mathrm{MI} \mathrm{Si-SiC} \mathrm{matrix} \mathrm{as} \mathrm{well}$ as the $0^{\circ}$ tows. Thus, in Type 3 damage the cracks are bridged by the fibers only. The three damage states are illustrated in Figure 9. In all three damage types, multiple cracks within the unit cell are possible. Crack density variations are simulated by varying the number of cracks in the unit cell. In the damage states illustrated in Figure 9, the cracks extend across the entire width and thickness of the unit cell. The CODs have been exaggerated in the figures for illustrative purposes. A multi-unit cell model was utilized to obtain the results at crack densities less than one crack per unit cell (less than $0.67 \mathrm{cracks} / \mathrm{mm}$ ). Undamaged unit cells were placed one after another to form a column and a single crack was placed in the middle of the column.

The numerical simulations of the unit cell under the three damage states were performed in the same manner as described in Section 5.0. The resistivity values listed in Table I were used for the Sylramic ${ }^{\mathrm{TM}}$ iBN fibers and the CVI SiC matrix. Based on the numerical solution results for the undamaged composite, the resistivity of the MI Si-SiC matrix was assumed to be $0.00745 \Omega$-cm. Again, the resistivity of the BN fiber coating was treated as a variable. To illustrate the effect of each damage state, the results are quantified using the resistivity ratio. The resistivity ratio is the ratio of the effective resistivity in a specific damage state to the initial (undamaged) effective resistivity.

Figure 10 is a summary of the unit cell analysis results for a variety of idealized damage states. The resistivity ratio is plotted versus crack density for each of the three damage types. All results shown in Figure 10 are from solutions that used a BN resistivity of $10^{5} \Omega$-cm and a COD of $1 \mu \mathrm{m}$. Note that Type 1 damage has an insignificant effect on the composite ER. For this damage type, the resistivity ratio remains close to unity even at a large crack density. In contrast, Type 2 and Type 3 damage have a very significant effect on the ER.

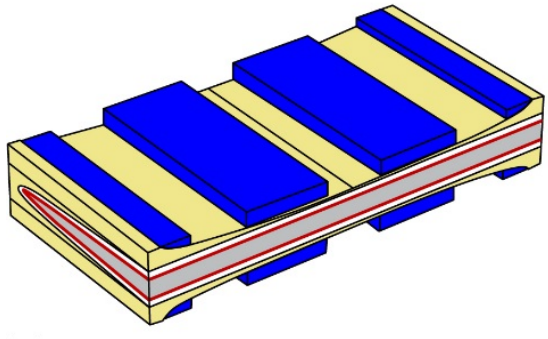

(a)

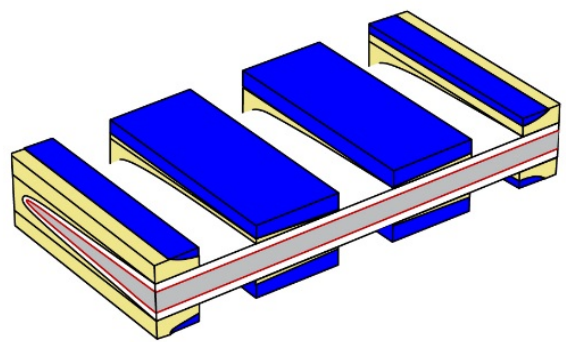

(b)

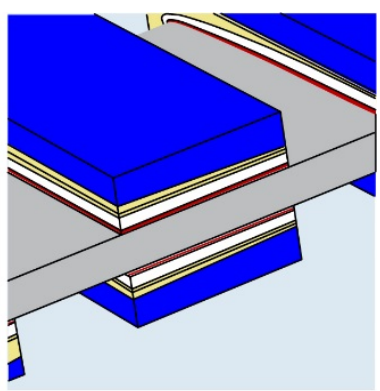

(c)

Figure 9.-One-half-symmetry unit cell models illustrating various damage states; images generated by COMSOL (COMSOL, 2016). (a) Type 1: Cracking of $90^{\circ}$ tows only. (b) Type 2: Cracking of $90^{\circ}$ tows and MI Si-SiC matrix. (c) Type 3: All constituents cracked except $0^{\circ}$ fibers. 


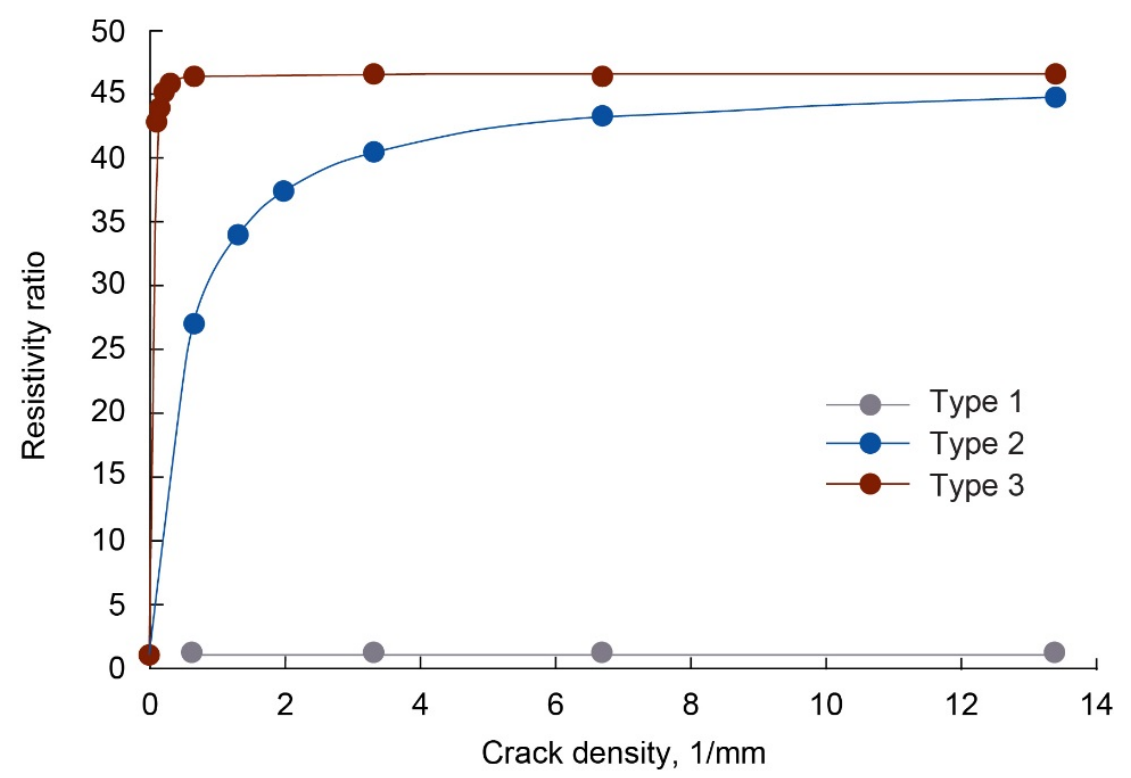

Figure 10.-Numerical solution results of resistivity ratio versus crack density for the three damage types. Results obtained with resistivity of BN fiber coating $\rho_{B N}=10^{5} \Omega-\mathrm{cm}$ and crack opening displacement of $1 \mu \mathrm{m}$.

The only difference between the Type 1 and Type 2 damage states is that Type 2 damage includes cracking in the MI Si-SiC matrix. The large differences between the Type 1 and Type 2 resistivity ratios highlight the significance of MI Si-SiC matrix cracking. Indeed, the unit cell resistivity is particularly sensitive to MI Si-SiC matrix cracking. This should not be surprising, as one would expect that cracking of the most conductive constituent would have the most significant effect on the composite resistivity.

In the Type 2 and Type 3 damage states, the resistivity ratio increases with crack density. For Type 3 damage, the resistivity ratio rises rapidly at a very low crack density. In Type 2 damage, electrons in the MI Si-SiC matrix must travel into the CVI SiC matrix in order to traverse a matrix crack. In the Type 3 damage, electrons in the MI Si-SiC matrix must travel across the CVI SiC matrix and BN fiber coating and into the fiber in order to traverse a matrix crack. Thus, every matrix crack presents a constriction to the current flow. The more cracks there are, the higher the resistance.

Note that the highest resistivity ratio shown in Figure 10 is approximately 46.5. This is the upper limit on the resistivity ratio for this set of constituent resistivity values and microstructure geometry. The upper limit is reached when the current flow constrictions caused by matrix cracking is so severe that current will only flow within the bridging fibers. For the Type 3 cracking damage results shown in Figure 10, the upper limit is reached at a crack density of less than one crack per mm (one crack per unit cell). This is the result of the high resistivity of the CVI SiC matrix and the high value used for the BN fiber coating in these analysis solutions $\left(10^{5} \Omega\right.$-cm). Given this set of constituent resistivity values, the electrons will effectively only flow within the fibers even though there is only one crack within the unit cell. 


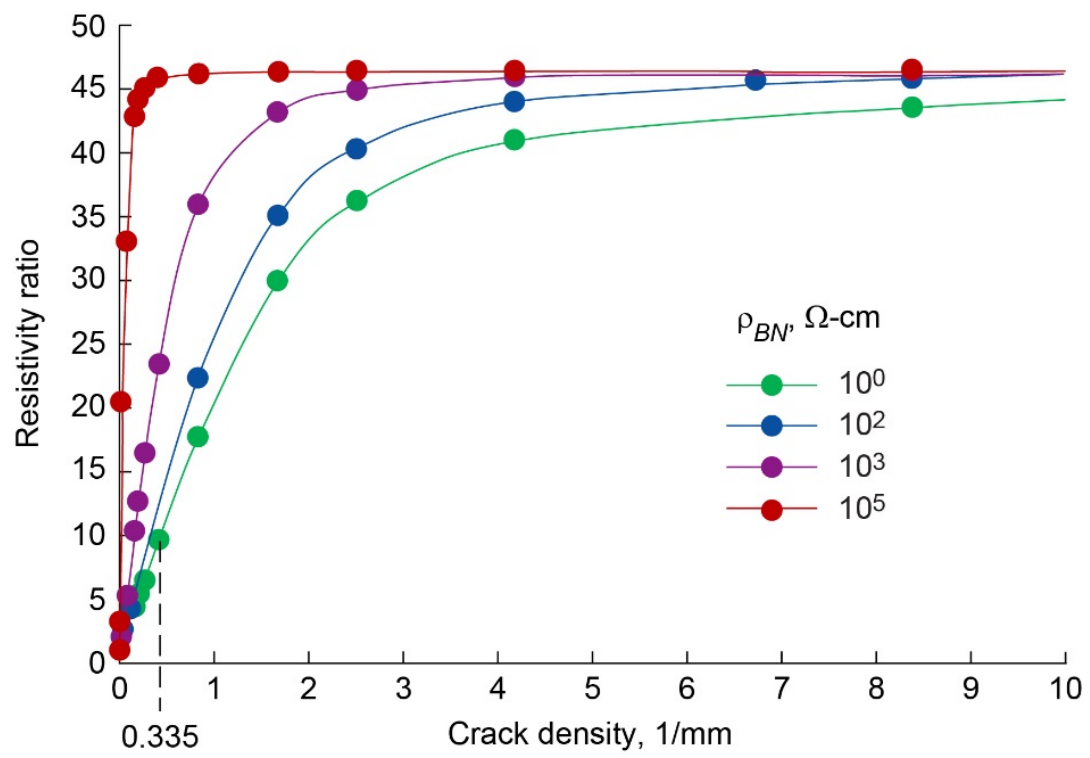

Figure 11.-Numerical solution results of resistivity ratio versus crack density for Type 3 damage showing effect of BN resistivity $\rho_{B N}$. Results obtained at crack opening displacement of $1 \mu \mathrm{m}$.

Figure 11 illustrates the effect of the BN resistivity on the unit cell effective resistivity for the Type 3 damage states. The resistivity ratio is plotted versus crack density for a variety of BN resistivity values. In all cases, the resistivity ratio increases with crack density and approaches the upper limit at high crack densities. The value of the BN resistivity determines the rate of increase and the value of the crack density at which the upper limit is reached. For reasons previously discussed, a higher BN resistivity yields a higher rate of increase. Thus, at any given crack density, the resistivity ratio increases with the BN resistivity. This effect is only significant at low crack densities, as all the curves tend to converge at higher crack densities. All results obtained using BN resistivity values greater than $10^{5} \Omega$-cm are nearly identical to the results obtained using a value of $10^{5} \Omega$-cm.

In all preceding analysis solutions, the COD was fixed at $1 \mu \mathrm{m}$. The COD is a function of several variables. Notably, it is an increasing function of the applied tensile stress magnitude (Marshall, Cox, and Evans, 1985). The effect of the COD on the effective resistivity can be easily determined using the finite element model. In Figure 12, the unit cell resistivity ratio is plotted versus the COD for various BN resistivity values. Figure 12(a) and (b) show the results for a crack density of 2.01 cracks $/ \mathrm{mm}$ (3 cracks per unit cell) and 3.35 cracks/mm (5 cracks per unit cell), respectively. Note that for all BN resistivity values and for both crack densities, the resistivity ratio is independent of the COD.

Another cracking feature that may contribute to an increase in the composite resistivity is debonding between the fibers and the matrix. It has been well chronicled by many previous authors (e.g., see Aveston, Cooper, and Kelly, 1971; Marshall, Cox, and Evans, 1985; and Thouless and Evans, 1988) that matrix cracks that are bridged by fibers are accompanied by debonding between the fibers and the matrix. The debond extends from the matrix crack planes along a certain length in the fiber direction. In composites with a fiber coating, the debonding occurs either between the fibers and the fiber coating or between the fiber coating and the matrix. In addition, these interfaces may become worn during cyclic loading, which may reduce the amount of contact between the constituents. The ability of the electrons in the CVI or MI Si-SiC matrix to traverse the matrix cracks depends on their ability to travel across the BN fiber coating and into the fibers. Debonding and interfacial wear in the vicinity of the matrix cracks may cause an overall reduction in the rate of current flow through the cracked microstructure. 

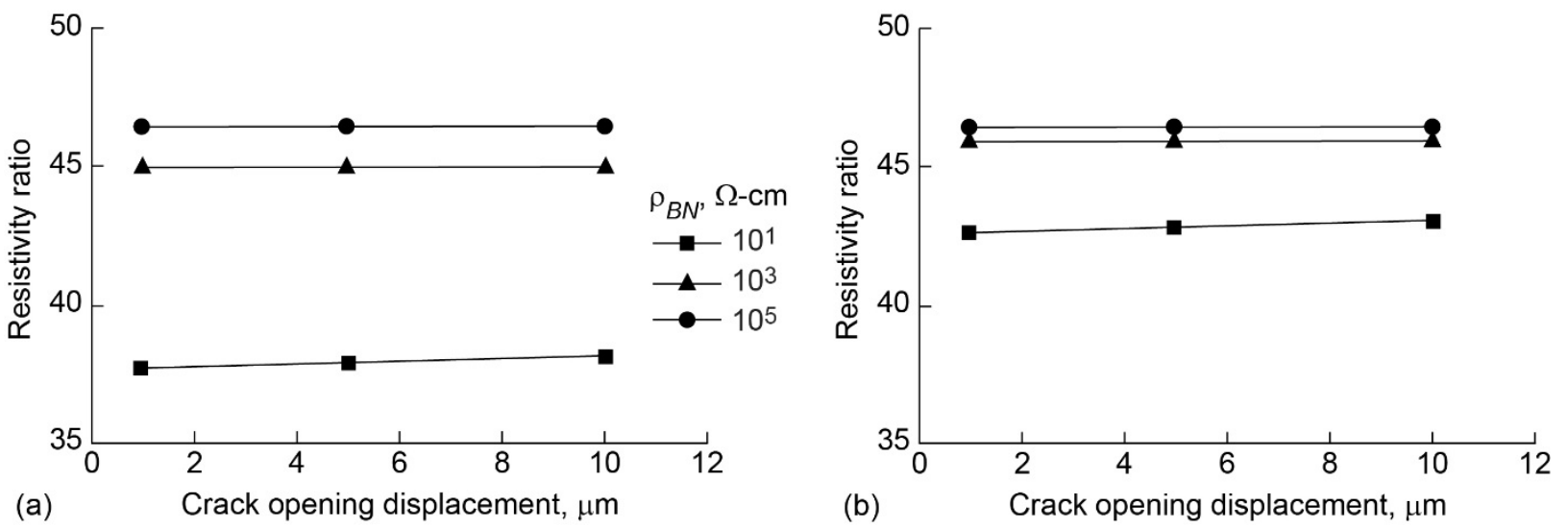

Figure 12.-Numerical solution results for resistivity ratio versus crack opening displacement for Type 3 damage and various $B N$ resistivity $\rho_{B N}$ values. (a) $2.01 \mathrm{cracks} / \mathrm{mm}$. (b) $3.35 \mathrm{cracks} / \mathrm{mm}$.

One way to numerically simulate the effect of a debond and interfacial wear between the fibers and the $\mathrm{BN}$ coating or between the $\mathrm{BN}$ coating and the CVI SiC matrix is to increase the BN resistivity value along a length equal to the debond length on both sides of the matrix crack. A simpler approach to capture this effect would be to increase the BN resistivity along the entire length of the $0^{\circ}$ tows within the unit cell. The results of this approach have already been presented in Figure 11. In view of the results shown in Figure 11, it appears that the effect of debonding on the composite resistivity depends upon the crack density and the value of the pristine (or undebonded) BN resistivity. For example, if the resistivity of the pristine BN is less than $10^{3} \Omega$-cm, then increasing the resistivity by 2 or 3 orders of magnitude can cause a significant increase in the composite resistivity, particularly at low crack densities. However, if the pristine BN resistivity is $10^{4} \Omega$-cm or more, then any increase in the BN resistivity will not result in a significant increase in the composite resistivity. In order to quantify the increase in the composite resistivity due to fiber/matrix debonding and interfacial wear, it is necessary to obtain the intrinsic resistivity of the pristine BN fiber coating.

Smith (2016) measured the resistivity as a function of stress in the gage section of composite tensile specimens. The tensile specimens were cut from panels of the same composite material described in Section 2.0 of this report. Smith also measured the crack density as a function of stress using a similar set of specimens. The crack density was measured through microscopic images by counting the number of cracks that intersect a tow. An average crack density was obtained by taking the average number of intersections over multiple tows within the image. Combining the two sets of data, the composite resistivity (and resistivity ratio) can be obtained as a function of the crack density. These results are plotted as the green circular markers in Figure 13(a). Notice that the maximum measured resistivity ratio is approximately 10 and it occurs at an average crack density of approximately 12 cracks $/ \mathrm{mm}$.

Cracks that develop in the gage section of the tensile specimen are of two varieties: (1) cracks that extend across the entire width and depth of the gage section (fully extended) and (2) cracks that extend across only a fraction of the width and/or depth (partially extended). The numerical analyses of all damage states discussed thus far in this report involve a unit cell with cracks extending across its entire depth and width. Since the unit cell is a representative volume of the composite, the results shown in Figure 10 through Figure 12 are representative of the effects of fully extended cracks. The numerical results for the fully extended cracks with a Type 3 damage state, which were shown previously in Figure 10, are also plotted in Figure 13(a). These results are plotted as the solid blue line in Figure 13(a). Notice that, at all crack densities, the predicted resistivity ratios obtained previously for the Type 3 damage states with fully extended cracks are much higher than the resistivity ratios obtained in Smith’s experiments. 


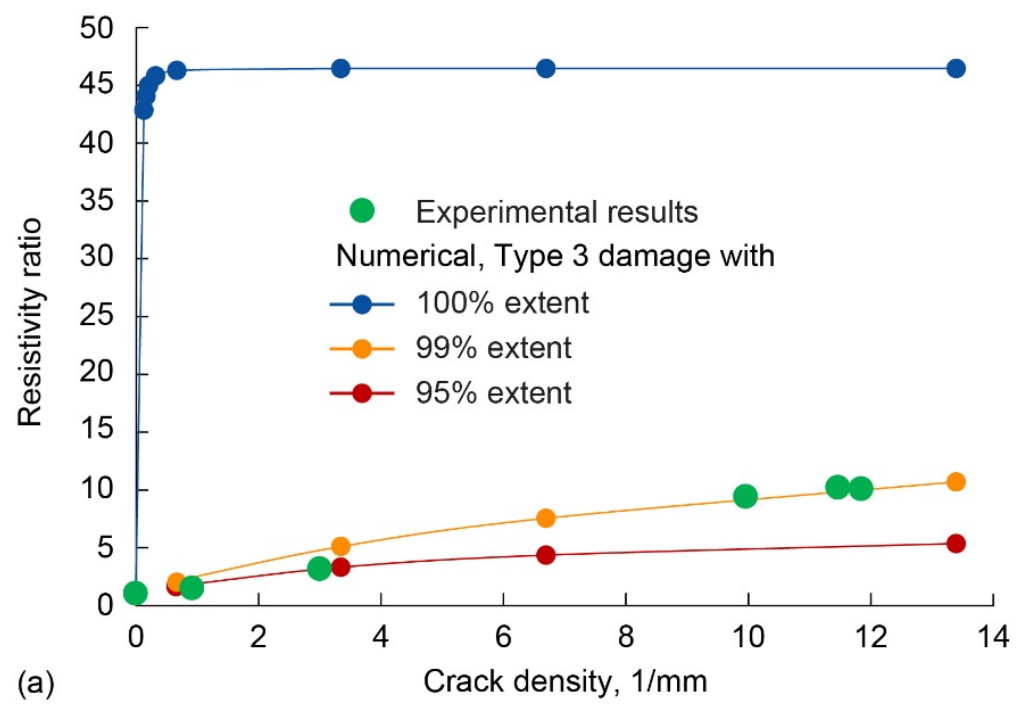

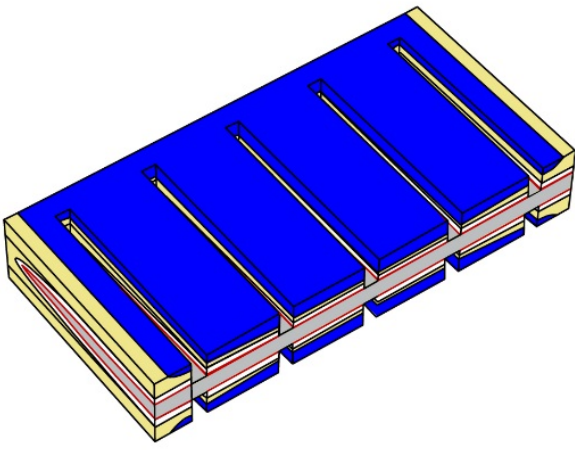

(b)

Figure 13.-Numerical results for Type 3 damage, illustrating the effect of extent of cracking. (a) Resistivity ratio plotted versus crack density. Numerical results obtained using BN resistivity $\rho_{B N}=10^{5} \Omega-\mathrm{cm}$ and crack opening displacement of $1 \mu \mathrm{m}$. Experimental results are from Smith (2016). (b) Unit cell showing partially extended cracks.

A rigorous analysis of partially extended cracks within the gage section would require a macroscale analysis of the gage section with discrete partially extended cracks. The model would contain several unit cells. Since cracking is a random process, the cracks should be arranged with a random number generator, and the simulations should be performed over a large number of crack arrangements, consistent with the Monte Carlo method. Such analyses are beyond the scope of the current study. Alternatively, one may observe the approximate effects of the partially extended cracks through the analysis of a unit cell with partially extended cracks. An arrangement of partially extended cracks in the unit cell is shown in Figure 13(b). The numerical results for this arrangement are also shown in Figure 13(a). The results for cracks that extend across 95 and 99 percent of the unit cell width are plotted as the red and gold lines, respectively. These results are much closer to the measured results from Smith (2016). The arrangement of partially extended cracks provides a continuous path of uncracked MI Si-SiC matrix and, as a result, a much lower resistivity than the fully cracked case.

Of course, the crack arrangement shown in Figure 13(b) is contrived. Since crack formation is a random process, the crack arrangement should be more irregular than that shown in the figure. However, the results shown in Figure 13(a) indicate that up to the point of specimen failure, there are far more partially extended cracks in the gage section than fully extended cracks. If this were not the case, the measured resistivity would be much higher. This conclusion holds true regardless of the BN resistivity value. Indeed, the results shown in Figure 11 reveal that even at a BN resistivity as low as $1 \Omega$-cm, the fully extended crack density must be $0.335 \mathrm{cracks} / \mathrm{mm}$ or less in order for the composite resistivity ratio to remain $\leq 10$. A crack density of 0.335 cracks $/ \mathrm{mm}$ is equivalent to approximately 10 cracks within the gage length. If the $\mathrm{BN}$ resistivity is higher, the crack density must be even less for the composite resistivity ratio to remain $\leq 10$.

\subsection{Summary and Conclusions}

Finite element analyses were performed to simulate the electric current flow through a Sylramic ${ }^{\mathrm{TM}}$-iBN (COI Ceramics, Inc.) fiber-reinforced melt-infiltrated (MI) silicon carbide (SiC) composite microstructure in 
a variety of damage states. A unit cell was adopted to serve as a representative volume of the composite's periodic microstructure. The finite element analysis of the unit cell provided an estimate of the value of the intertow matrix resistivity, which was previously unknown, and insight into the significance of certain cracking features on the composite electrical resistivity (ER). The value of the boron nitride (BN) fiber coating resistivity is also unknown. The numerical solutions were performed for a range of BN resistivity values to investigate the significance of this parameter on the solution results.

Specifically, analysis of the unit cell in the undamaged state and in various damage states revealed that

1. The MI Si-SiC matrix resistivity is approximately $0.00745 \Omega$-cm. This estimate was obtained by comparing the analysis results for the undamaged unit cell to the undamaged composite ER measurements.

2. Cracking of the chemical-vapor-infiltrated $\mathrm{SiC}$ matrix in the $90^{\circ}$ tows has little to no effect on the composite ER, even at high crack densities.

3. Cracking of the MI Si-SiC matrix has the most profound effect on the composite ER. In this damage state, the resistivity is an increasing function of the crack density.

4. The value of the BN resistivity has very little effect on the undamaged composite resistivity; however, it may influence how the composite ER is affected by certain cracking features.

5. The effect of the crack opening displacement is insignificant.

6. Local fiber/matrix interface debonding at a matrix crack plane may result in a composite ER increase at low crack densities, if the BN resistivity is equal to or less than $10^{3} \Omega$-cm. Otherwise, the effect of fiber/matrix debonding is insignificant.

The second finding above suggests that cracking in the $90^{\circ}$ tows cannot be detected with an ER measurement. The third finding is not surprising, given that the MI Si-SiC matrix is the most conductive of all the constituents and that it occupies a significant percentage of the total volume. The sixth finding underscores the importance of determining the ER of the BN fiber coating. Future studies should include the development of a method to measure or deduce the in situ value of the pristine BN fiber coating resistivity.

\section{References}

Accuratus (2013): Boron Nitride Datasheet. http://accuratus.com/boron.html Accessed Jan. 25, 2018. Aldalbahi, Ali; Zhou, Andrew Feng; and Feng, Peter (2015): Variations in Crystalline Structures and Electrical Properties of Single Crystalline Boron Nitride Nanosheets. https://www.nature.com/articles/srep16703 Accessed Feb. 21, 2018.

Almansour, Amjad S. (2017): Use of Single-Tow Ceramic Matrix Minicomposites To Determine Fundamental Room and Elevated Temperature Properties. Ph.D. Dissertation, Univ. of Akron.

Aveston, J.; Cooper, G.A.; and Kelly, A. (1971): Single and Multiple Fracture. The Properties of Fiber Composites, Conference Proceedings of the National Physical Laboratory, IPC Science and Technology Press Ltd., Surrey, England, pp. 15-26.

Bousetta, Ming Lu, et al. (1996): Electrical Properties of Boron Nitride Thin Films Grown By Neutralized Nitrogen Ion Assisted Vapor Deposition. Appl. Phys. Lett., vol. 68, no. 5, pp. 622-624.

Budiansky Bernard; and Cui, Yingqing Lawrence (1994): On the Tensile Strength of a Fiber-Reinforced Ceramic Composite Containing a Crack-Like Flaw. J. Mech. Phys. Solids, vol. 42, no. 1, pp. 1-19.

Ceratec Technical Ceramics BV (2018): Boron Nitride Datasheet. http://www.ceratec.nl/materials.html Accessed Jan. 25, 2018. 
COMSOL, Inc. (2016): COMSOL Multiphysics User’s Guide. Version 5.2a.

DiCarlo, James A. (2004): Microstructural Optimization of High Temperature SiC/SiC Composites. Proceedings of the 5th International Conference on High Temperature Ceramic Matrix Composites, Seattle, WA.

Jones, Robert M. (1975): Mechanics of Composite Materials. McGraw-Hill Book Company, New York, NY.

Marshall, D.B.; Cox, B.N.; and Evans, A.G. (1985): The Mechanics of Matrix Cracking in Brittle-Matrix Fiber Composites. Acta Metall., vol. 33, no. 11, pp. 2013-2021.

Morscher, Gregory N.; and Gordon, Neal A. (2017): Acoustic Emission and Electrical Resistance in SiCBased Laminate Ceramic Composites Tested Under Tensile Loading. J. Eur. Ceram. Soc., vol. 37, pp. 3861-3872.

Precision Ceramics (2018): Boron Nitride Datasheet. http://www.precisionceramics.co.uk/materials/boron-nitride/ Accessed Jan. 25, 2018.

Smith, Craig E. (2016): Electrical Resistance Changes of Melt Infiltrated SiC/SiC Subject to Long-Term Tensile Loading at Elevated Temperatures. Ph.D. Dissertation, Univ. of Akron.

Smith, Craig E.; Morscher, Gregory N.; and Xia, Zhenhai (2011): Electrical Resistance as a Nondestructive Evaluation Technique for SiC/SiC Ceramic Matrix Composites Under Creep-Rupture Loading. Int. J. Appl. Ceram. Technol., vol. 8, no. 2, pp. 298-307.

Smith, Craig E.; Morscher, Gregory N.; and Xia, Z.H. (2008): Monitoring Damage Accumulation in Ceramic Matrix Composites Using Electrical Resistivity. Scr. Mater., vol. 59, no. 4, pp. 463-466.

Thouless, M.D.; and Evans, A.G. (1988): Effects of Pull-Out on the Mechanical Properties of Ceramic Matrix Composites. Acta Metall., vol. 36, no. 3, pp. 517-522.

Xia, Z.C.; and Hutchinson, J.W. (1994): Matrix Cracking of Cross-Ply Ceramic Composites. Acta Metall. Mater., vol. 42, no. 6, pp. 1933-1945. 


